Revista Destaques Acadêmicos, Lajeado, v. 10, n. 4, 2018. ISSN 2176-3070

DOI: http://dx.doi.org/10.22410/issn.2176-3070.v10i4a2018.1797

http://www.univates.br/revistas

\title{
MELHORIA DA EFICIÊNCIA ENERGÉTICA NO PROCESSO DE ROTOMOLDAGEM EM UMA EMPRESA
}

\author{
Everton Bertoldi ${ }^{1}$, Evandro Bertoldi ${ }^{2}$
}

\begin{abstract}
Resumo: Este estudo tem como objetivo melhorar a eficiência energética de um processo produtivo de rotomoldagem, otimizando o consumo de energia elétrica e gás liquefeito de petróleo (GLP), e mantendo a qualidade dos produtos produzidos. Foi desenvolvida uma investigação prática para acompanhar e entender o processo produtivo, e com base no referencial teórico, foi proposto ações para que o objetivo pudesse ser alcançado. As ações auxiliaram na definição dos parâmetros do processo, enfatizando o tempo de forno, identificado como principal causa dos problemas de peças não conformes. A partir da análise dos resultados referentes à peça estudada, observou-se que do total de 192.000 peças produzidas no período de um ano, 1,2\%, ou seja, 2.304 peças não puderam ser aproveitadas, pois não estavam em conformidade. Além disso, das 2.304 peças não conformes, $67 \%$, ou 1.544 peças, apresentaram problemas de imperfeições devido à falta de tempo no forno. A partir dos problemas com o processo de forno, foi possível comparar os custos consumidos em relação aos programados. Considerando a soma do custo do processo das peças não conformes (energia elétrica e GLP), o polietileno desperdiçado, o custo envolvido na trituração do polietileno desperdiçado, o custo do novo processo das peças a fim de atender ao pedido, e o polietileno para este novo processo, chegou-se ao custo total consumido. Desta forma, observou-se um desperdício de 39\% nos custos de fabricação gastos devido aos problemas evidenciados no processo de forno. Através dos resultados obtidos, concluiu-se que a eficientização energética de um processo produtivo não necessariamente precisa de altos investimentos. E além dos fatores econômicos, o estudo permitiu a realização de ajustes no procedimento interno dos setores da empresa envolvidos no processo produtivo.
\end{abstract}

Palavras-chave: Rotomoldagem. Eficiência energética. Definição de parâmetros. Otimização de consumos.

1 Engenheiro de Produção Mecânica - UPF.

2 Engenheiro Mecânico - UNIJUÍ. 


\section{INTRODUÇÃO}

O consumo demasiado de energia elétrica e combustíveis derivados do petróleo é um problema que a maioria das empresas enfrenta, principalmente em indústrias, como é o caso de empresas responsáveis pela transformação de polímeros através do processo de rotomoldagem. Para a fabricação das peças plásticas são consumidos, além de energia elétrica, o gás liquefeito de petróleo (GLP), e utiliza-se o polietileno como matéria-prima, o qual é um derivado do petróleo que trata-se de um recurso energético não renovável, gerando, assim, a necessidade de otimizar a sua aplicação.

A rotomoldagem consiste em um processo industrial em que se obtêm peças ocas, e como seu nome faz analogia, por meio do movimento de rotação biaxial de um molde abastecido com material termoplástico (BEALL, 1998). O molde é submetido ao aquecimento dentro de um forno, no qual a fusão e a transformação de uma determinada peça acontecem pela ação conjunta de temperatura e rotação. É através da força centrífuga que o material copia os detalhes do molde do produto. A máquina de rotomoldagem é composta por braços onde se encontram os pratos, local onde os moldes são fixados, podendo produzir várias peças em um único ciclo de trabalho.

Durante o processo produtivo, muitas vezes acontecem, por necessidade de atender o cliente através de um pedido de produção inesperado, ou até mesmo, devido a falta de conhecimento do processo, a má distribuição dos moldes na máquina de rotomoldagem, gerando, assim, um desperdício energético. O planejamento da produção, isto é, a definição dos moldes a serem montados, deve respeitar os parâmetros de processo para cada molde, evitando desperdício energético em cada ciclo de produção e até mesmo desperdício com peças não conformes, o que acaba gerando um prejuízo ainda maior à empresa, além de não satisfazer a necessidade do cliente.

Desta forma tem-se como objetivo neste trabalho, melhorar a eficiência energética de um processo produtivo de rotomoldagem, otimizando o consumo de energia elétrica e GLP, mantendo a qualidade dos produtos produzidos.

\section{REFERENCIAL TEÓRICO}

$\mathrm{O}$ processo de rotomoldagem, também conhecido por moldagem rotacional, é o processo que se dá por meio do aquecimento de materiais poliméricos no qual a fusão e a transformação de uma determinada peça acontecem pela ação conjunta de temperatura e rotação. Tal processo possibilita a confecção de peças plásticas ocas mediante adição de plástico em pó em um molde que é aquecido e que roda em dois eixos (CRAWFORD; THRONE, 2002). É através da força centrífuga que o material copia os detalhes do molde do produto.

A matéria-prima que mais se destaca neste processo é o polietileno, o qual é fornecido na forma de pellets, isto é, pequenos grãos, sendo necessário 
passar por um processo de micronização, transformando-o em pequenas partículas. Quando há necessidade de se produzir peças coloridas, este polietileno micronizado passa por outro processo antes de ser rototomoldado, que é o processo de pigmentação. A Figura 1 apresenta o polietileno em três formas: peletizado, micronizado e pigmentado.

Figura 1 - Polietileno em três formas o qual é mostrado da esquerda para a direita: polietileno peletizado, micronizado, e pigmentado

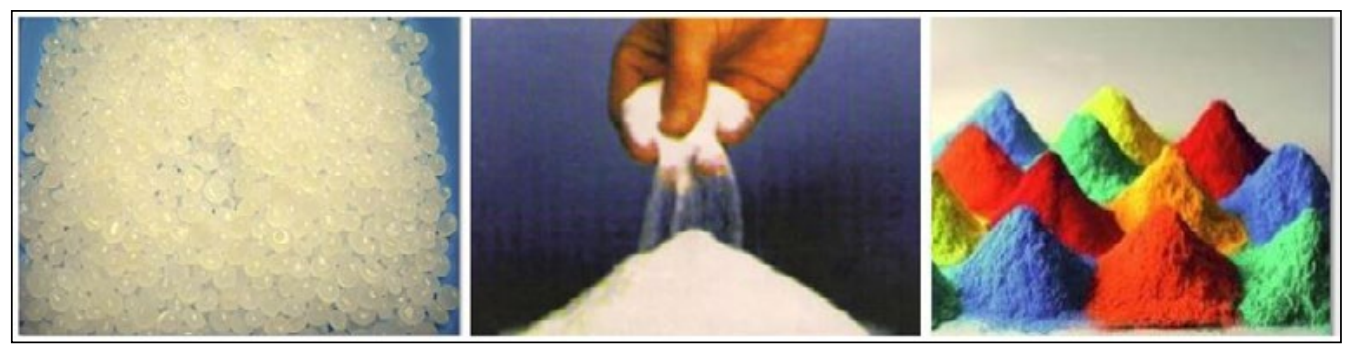

Fonte: Autor.

O polietileno representando aproximadamente $90 \%$ do material consumido na indústria de rotomoldagem, e, dependendo das condições reacionais e do sistema catalítico empregado na polimerização, alguns tipos de polietilenos podem ser produzidos, por exemplo: polietileno de alta densidade (PEAD), polietileno de média densidade (PEMD), e polietileno de baixa densidade (PEBD). O PEBD apresenta cerca de 50\% de cristalinidade, enquanto PEAD possui $80 \%$. Além disso, a presença de ramificações grandes no PEBD dificulta o processo de cristalização, tornando o polímero menos cristalino e com cristalitos de menor perfeição, e consequentemente menor densidade (CANEVAROLO, 2006). As ramificações estão diretamente relacionadas às características dos materiais. Enquanto que o PEBD apresenta ramificações longas, o PEAD apresenta ramificações curtas (COUTINHO; MELLO; DE SANTA MARIA, 2003).

O processo básico da rotomoldagem é composto de quatro etapas conforme descritos abaixo e mostrado na Figura 2.

- Carregamento: onde o molde é alimentado com a matéria-prima, neste caso, o polietileno;

- Aquecimento: etapa em que o molde é levado ao aquecimento em um forno, que através do efeito sinérgico entre o calor recebido do forno e a movimentação biaxial, moldam a peça no interior do molde;

- Resfriamento: ainda em movimento de rotação o molde é conduzido a uma área composta de ventiladores para que o material já distribuído de modo uniforme na espessura projetada ganhe a forma final do produto; 
- Descarga: etapa final que acontece em uma área especial, na qual a peça resfriada é retirada cuidadosamente do molde.

Figura 2 - Etapas do processo de rotomoldagem

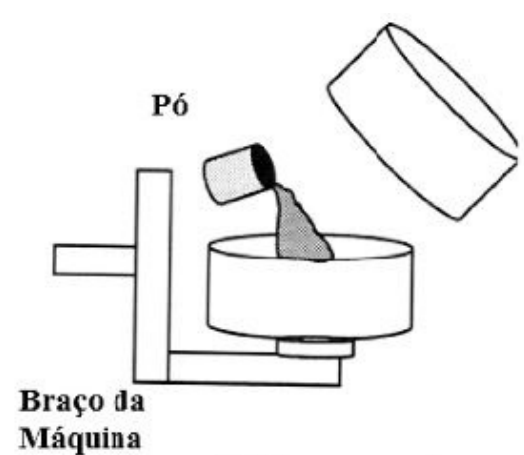

(a) Carregamento

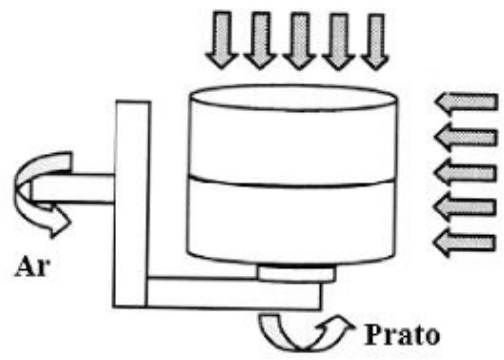

(c) Resfriamento

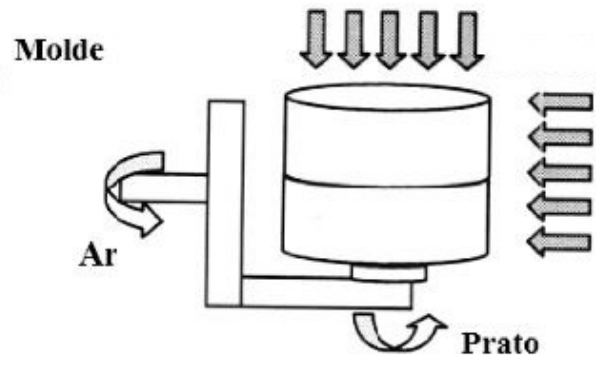

(b) Aquecimento

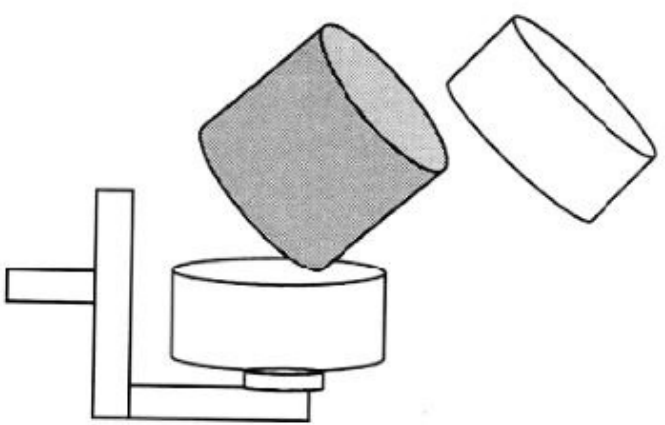

(d) Descarga

Fonte: Adaptado de NUGENT, 2001.

Após resfriadas, as peças passam por processos de acabamento. Primeiramente é necessária a remoção da rebarba resultante da linha de fechamento do molde, podendo ser seguido de furações, cortes, e montagem de componentes. Estas etapas dependerão da necessidade do projeto de cada peça produzida.

Os produtos rotomoldados passaram a ser produzidos na década de 1950 e são destaques na indústria de reservatórios, brinquedos, componentes automotivos, entre outros (CRAWFORD; THRONE, 2002). O material mais utilizado no processo é o polietileno (PE), sendo a classe do polietileno linear de baixa densidade (PELDB) o que ganha destaque. Ressalta-se que para se ter êxito neste processo produtivo, a escolha da matéria-prima adequada é fundamental, uma vez que o polímero empregado necessita atender as características de viscosidade e de resistência térmica e química para não sofrer 
degradação termo-oxidativa devido a longos períodos de permanência no forno (BEALL, 1998).

Os principais campos de aplicação do processo de rotomoldagem são os setores agrícola, automotivo, construção, eletrônico, indústria, produtos marinhos, recreação, entre outros (NUGENT, 2001). De acordo com Crawford e Throne (2002), para se especificar uma máquina de rotomoldagem são considerados, basicamente, os seguintes parâmetros:

- Capacidade de aquecimento;

- Tamanho do forno;

- Tempo médio por ciclo;

- Velocidade de rotação do molde.

A partir destas variáveis podem existir diferentes classes de máquinas de rotomoldagem, cada uma com suas particularidades. Em Crawford e Throne (2002) são apresentados diversos modelos de máquinas de rotomoldagem, seus principais componentes e princípios de funcionamento. Já em Crawford e Kearns (2003) é apresentado as características de um molde de rotomoldagem de acordo com a complexidade das peças que pretende-se fabricar. Quanto aos parâmetros deste processo de fabricação, Crawford e Throne (2002) e Godinho (1997) descrevem detalhadamente os aspectos que devem ser observados em relação ao aquecimento, monitoramento da temperatura, e resfriamento.

\section{METODOLOGIA}

A metodologia aplicada para atingir os objetivos apresentados inicia com o referencial teórico referente ao tema proposto, seguido da avaliação do atual processo produtivo, onde foi possível propor algumas ações, e posteriormente, mensurar e comparar os consumos. A metodologia é apresentada a partir do fluxograma da Figura 3.

A partir do referencial teórico pretende-se estudar os mais importantes conceitos, justificativas, e características sobre o desenvolvimento, permitindo, assim, embasamento e servindo como comparação em relação aos resultados. Através da avaliação do atual processo produtivo, pretende-se apresentar o diagnóstico do problema levantado neste trabalho para, em seguida, identificar os pontos importantes e relevantes que devem ser levados em consideração na proposta de melhoria. Por fim, após identificada e realizada as ações para a problemática levantada, é possível apresentar os resultados alcançados através da proposta desenvolvida. 
Figura 3 - Metodologia aplicada

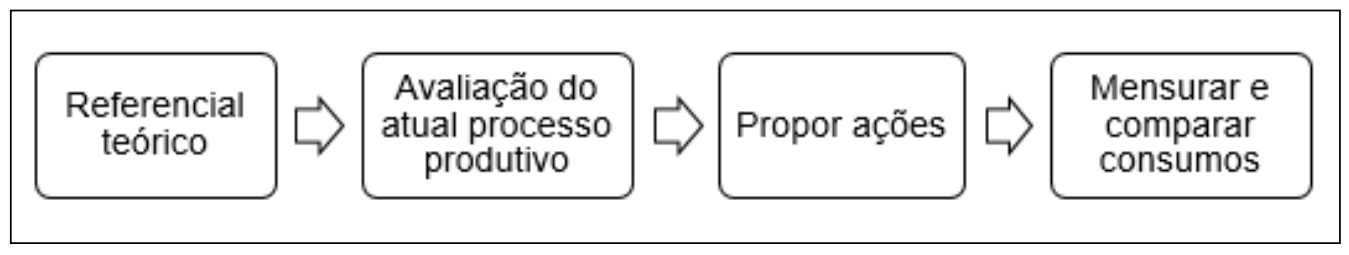

Fonte: Autor.

Buscando a otimização do consumo de energéticos no processo de rotomoldagem, foi realizado um acompanhamento do dia a dia de uma determinada empresa fabricante de produtos rotomoldados, a fim de melhorar o entendimento e conhecimento prático de todo o processo, desde a programação da produção até o acabamento das peças produzidas. Ao investigar o processo constatou-se que os parâmetros da principal etapa do processo, o aquecimento, não estavam sendo respeitados, o qual está diretamente ligado à eficiência energética, pois a mesma consome energéticos como o GLP, energia elétrica, além do material processado ser derivado do petróleo, que é uma energia não renovável. Tal fato pôde ser evidenciado ao final de alguns ciclos de produção, onde esporadicamente o processo resultava em peças mal acabadas, isto é, o polietileno não estava totalmente fundido, ou as peças estavam degradadas por excesso de energia térmica. Estes problemas podem ser identificados durante o processo de acabamento das peças rotomoldadas, onde também é realizado a inspeção da qualidade do processo.

Diante disto, foi verificado o indicador de peças não conformes, o qual apresentou um índice de $1,2 \%$ de peças rejeitadas no último ano, sendo que $67 \%$ destas com problemas relacionados com a etapa de aquecimento, isto é, peças com má formação ou peças degradadas.

$\mathrm{O}$ processo de distribuição e montagem dos moldes nas máquinas, etapa que antecede o processo de rotomoldagem, é realizado através do planejamento e controle da produção (PCP) com acompanhamento direto do supervisor ou líderes de células da produção, os quais possuem um maior conhecimento prático. Nesta etapa foi evidenciado que para alguns envolvidos, o entendimento que se tem é que a eficiência do processo está ligada somente ao aproveitamento total do prato da máquina. Em função disso, ocorrem montagens de moldes de parâmetros diferentes resultando em um mau agrupamento dos mesmos, deixando de lado a eficácia do processo como um todo. Além deste mau entendimento, também foi verificado que este procedimento acontece em função da ânsia de atender o cliente no prazo ou a entrada de um pedido de produção inesperado. Ambas as decisões de montagem dos moldes ocasionaram desperdícios de alguma forma. 
Diante desta abordagem, foi buscado maiores informações através de uma revisão bibliográfica, tendo como objetivo propor alguma ação para otimizar o consumo dos energéticos, reduzindo os desperdícios gerados no atual processo produtivo, a fim de garantir a eficientização do processo aliado a produção de peças de boa qualidade.

Verificou-se a importância do controle da temperatura interna do molde durante o processo, sendo utilizado instrumentos específicos para este controle, como por exemplo o Rotolog. As determinações dos parâmetros do processo, como tempo de forno e tempo de resfriamento, são realizadas com auxílio deste instrumento, o qual dependerá de algumas variáveis, como por exemplo, tamanho, espessura e material do molde, e espessura e material da peça a ser produzida.

Há varias consequências negativas quanto ao desrespeito ou má definição dos parâmetros do processo. Ciclos com pouco tempo de forno faz com que o polietileno não seja totalmente fundido. Ciclos prolongados acabam degradando o material da peça, e podem ser divididos em duas fases, sendo que na primeira fase acontecerão perdas das características do material, as quais são mais difíceis de serem identificadas dentro da empresa, gerando consequências negativas a imagem da empresa, pois haverá quebra prematura e necessidade de reposição das peças em campo. A segunda fase são tempos de ciclos extrapolados, que acarretarão, além da perda da peça, a manutenção do molde, pois nesta fase a peça acaba grudando no mesmo, gerando assim um custo adicional a ser contabilizado juntamente com os desperdícios que envolvem a produção e o descarte da peça. Todas as peças não conformes são trituradas internamente e o material é vendido a uma empresa recicladora, envolvendo todo um custo com desperdício de produção e trituração do material desperdiçado.

Atualmente a empresa produz peças para vários segmentos, principalmente para o segmento agrícola que se destaca com cerca de $90 \%$ da produção. O portfólio conta com aproximadamente 1000 produtos, os quais variam quanto à geometria, tamanho, cor, e peso, variando de 0,2 a $500 \mathrm{~kg}$. A empresa possui vários modelos de máquinas de rotomoldagem, sendo duas destas do modelo carrossel, onde este trabalho será enfatizado, pois são máquinas de alta produção e que são alimentadas por uma maior variedade de moldes. Esta máquina pode ser alimentada por vários moldes, pois possui quatro braços. Os moldes das peças produzidas nesta máquina são fabricados em alumínio, sendo que a empresa também possui moldes em chapa metálica, o qual são aplicados em peças maiores que são produzidas em outras máquinas de rotomoldagem. A etapa de pré-resfriamento e resfriamento é feita através de fluxo de ar forçado. A Figura 4 ilustra o modelo de máquina que foi estudado. 
Figura 4 - Ilustração da máquina de rotomoldagem tipo carrossel com três braços

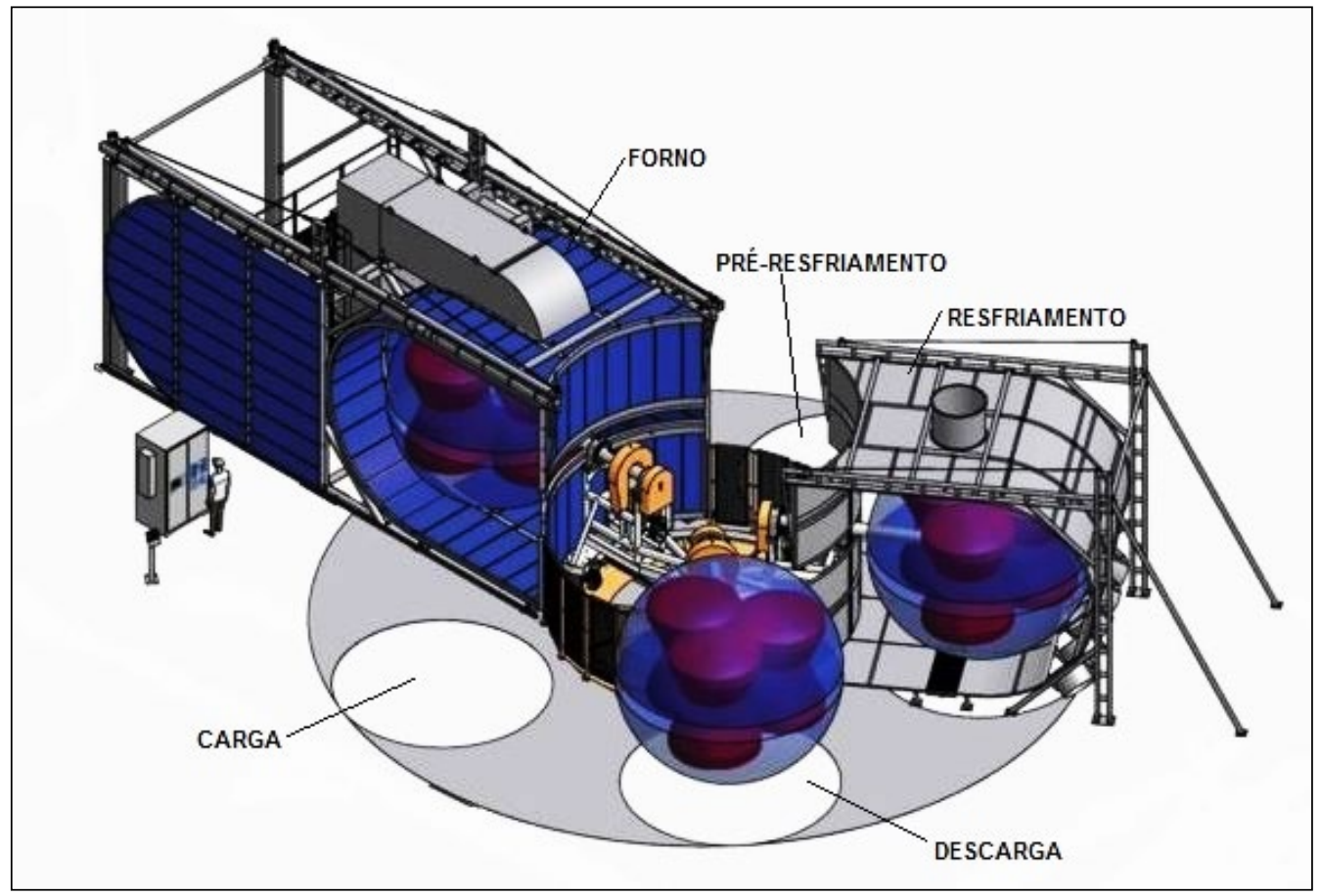

Fonte: Adaptado de ROTOLINE BRASIL, 2017.

A empresa utiliza polietileno de baixa densidade (PEBD) como matériaprima, sendo que cerca de $85 \%$ da produção utiliza polietileno extrudado e os demais são micronizados e pigmentados a seco em uma empresa terceirizada. A aplicação do polietileno extrudado está em uma crescente em função da sua qualidade. Em função disto, será abordada somente a aplicação do polietileno extrudado no presente trabalho.

A definição dos parâmetros do processo que antes era feita através da experiência dos operadores e supervisor da produção na prática, ou tentativa e erro, passou a ser controlado pelo instrumento de medição Rotolog, porém sendo aplicado apenas para novos desenvolvimentos em casos específicos, considerados processos críticos. Apesar da aquisição do instrumento, se constatou certa resistência quanto à aplicação do mesmo, o que acaba dependendo muito da experiência do supervisor da produção.

Diante disto, foram propostas duas ações. A primeira ação realizada é a utilização do instrumento para qualquer novo desenvolvimento, por mais simples que o produto seja, assim a definição dos parâmetros passa a ser realizada somente através do instrumento adquirido. Também passará a ser controlado todos os moldes que entrarem em produção através do controle e 
monitoramento da temperatura para confirmação ou ajuste dos seus parâmetros. Isto será realizado até que todo o portfólio esteja conforme. A segunda ação é fazer a classificação dos moldes através de famílias que apresentarem parâmetros semelhantes, sendo estas lançadas em uma lista mestra de moldes e posteriormente cadastradas junto ao software de gestão da produção. Assim sendo, o PCP passa a ter liberdade para programar a montagem dos moldes sem a necessidade e dependência dos líderes ou supervisor da produção. Esta segunda ação se deve ao grande número de moldes e variedades de peças, garantindo que peças de parâmetros semelhantes sejam produzidas juntas.

Desta forma, todos os moldes deverão ter seus parâmetros definidos de acordo com a temperatura interna do mesmo, o qual definirá os parâmetros do processo. Tais parâmetros passarão para uma lista mestra de moldes, na qual constará além de parâmetros de tempo, a família a qual pertence e as dimensões dos moldes, auxiliando, assim, a tomada de decisão na programação da produção. O Apêndice A apresenta parcialmente a lista mestra dos moldes.

Durante a investigação do processo, foram realizadas buscas do histórico de consumo e realizados alguns cálculos para se chegar ao consumo dos energéticos envolvidos no processo. De acordo com informação da empresa, através de indicadores históricos da mesma, o consumo de GLP para a máquina enfatizada neste trabalho é de $0,3 \mathrm{~kg}$ para cada $1 \mathrm{~kg}$ de polietileno processado.

Para mensurar o custo energético do processo, foram primeiramente identificados os motores elétricos da máquina de rotomoldagem em estudo, do moinho triturador, bem como o sistema de iluminação (composta de sete lâmpadas distribuídas), os quais estão relacionados na Tabela 1. Ambas as potências foram extraídas através de instrumento de medição.

Como há um grande número de variedade de peças, foi considerado um produto como exemplo para fins de cálculos e análise do consumo gerado. $\mathrm{O}$ produto escolhido para este estudo possui as seguintes características e parâmetros de processo:

- Nome da peça: Funil;

- Peso: 6,5 kg;

- Espessura: $5 \mathrm{~mm}$;

- Dimensões: 700 x 420 x 350 mm;

- Peças por suporte: 8 peças;

- Tempo de forno: $17 \mathrm{~min}$;

- Tempo de pré-resfriamento: $8 \mathrm{~min}$;

- Tempo de resfriamento: $14 \mathrm{~min}$. 
Tabela 1 - Relação dos consumidores

\begin{tabular}{c|c|c|c}
\hline \multirow{2}{*}{ Motor } & \multirow{2}{*}{ Localização } & \multicolumn{2}{|c}{ Potência } \\
\cline { 3 - 4 } & & $\mathbf{h p}$ & $\mathbf{k W}$ \\
\hline A & queimador & 1 & 0,75 \\
\hline B & turbina & 20 & 14,91 \\
\hline C & exaustor fumo & 4 & 2,98 \\
\hline D & porta 1 & 0,5 & 0,37 \\
\hline E & porta 2 & 0,5 & 0,37 \\
\hline F & ventilador 1 & 2 & 1,49 \\
\hline G & ventilador 2 & 2 & 1,49 \\
\hline H & exaustor refrigeração & 7,5 & 5,59 \\
\hline I & ventilador 3 & 2 & 1,49 \\
\hline J & ventilador 4 & 2 & 1,49 \\
\hline K & ventilador 5 & 2 & 1,49 \\
\hline L & eixo/braço & 2 & 1,49 \\
\hline M & prato & 3 & 2,24 \\
\hline N & roda & 2 & 1,49 \\
\hline SI & sistema iluminação & - & 0,40 \\
\hline MT & motor triturador & 30 & 22,37 \\
\hline
\end{tabular}

Fonte: Autor.

\section{RESULTADOS}

Através da avaliação do atual processo produtivo e com base nas informações coletadas, calcularam-se os valores de consumo em $\mathrm{kWh}$ para o processo de produção, os quais são apresentados na Tabela 2. Observa-se, a partir da Tabela 2, que os valores calculados para o consumo de energia elétrica, de acordo com os dados coletados, são apresentados separadamente para cada subprocesso. A nomenclatura utilizada para identificar os motores relacionados em cada subprocesso é mostrada na Tabela 1. 
Tabela 2 - Consumo de energia elétrica no processo

\begin{tabular}{|c|c|c|c|c|c|c|c|c|}
\hline \multicolumn{10}{|c|}{ Processo de forno } \\
\hline Motor & D & E & L & M & N & A & B & C \\
\hline Potência (kW) & 0,37 & 0,37 & 1,49 & 2,24 & 1,49 & 0,75 & 14,91 & 2,98 \\
\hline Tempo (h) & 0,01 & 0,01 & 0,29 & 0,29 & 0,01 & 0,28 & 0,28 & 0,28 \\
\hline Total (kWh) & \multicolumn{10}{|c|}{$\mathbf{6 , 3 9}$} \\
\hline
\end{tabular}

\begin{tabular}{|c|c|c|c|c|c|}
\hline \multicolumn{7}{|c|}{ Processo de pré-resfriamento } \\
\hline Motor & L & M & N & F & G \\
\hline Potência $(\mathrm{kW})$ & 1,49 & 2,24 & 1,49 & 1,49 & 1,49 \\
\hline Tempo (h) & 0,14 & 0,14 & 0,01 & 0,13 & 0,13 \\
\hline Total (kWh) & \multicolumn{5}{|c|}{$\mathbf{0 , 9 4}$} \\
\hline
\end{tabular}

\begin{tabular}{|c|c|c|c|c|c|c|c|}
\hline \multicolumn{10}{|c|}{ Processo de resfriamento } \\
\hline Motor & L & M & N & H & I & J & K \\
\hline Potência $(\mathrm{kW})$ & 1,49 & 2,24 & 1,49 & 5,59 & 1,49 & 1,49 & 1,49 \\
\hline Tempo $(\mathrm{h})$ & 0,24 & 0,24 & 0,01 & 0,23 & 0,23 & 0,23 & 0,23 \\
\hline Total (kWh) & \multicolumn{7}{|c|}{$\mathbf{3 , 2 6}$} \\
\hline
\end{tabular}

\begin{tabular}{|c|c|c|c|c|}
\hline \multicolumn{5}{|c|}{ Deslocamento para carga/descarga } \\
\hline Motor & L & M & N & N \\
\hline Potência $(\mathrm{kW})$ & 1,49 & 2,24 & 1,49 & 1,49 \\
\hline Tempo (h) & 0,01 & 0,01 & 0,01 & 0,01 \\
\hline Total (kWh) & \multicolumn{5}{|c|}{$\mathbf{0 6 6}$} \\
\hline
\end{tabular}

\begin{tabular}{|c|c|}
\hline \multicolumn{2}{|c|}{ Sistema de iluminação } \\
\hline Lâmpadas & SI \\
\hline Potência $(\mathrm{kW})$ & 2,80 \\
\hline Tempo $(\mathrm{h})$ & 0,70 \\
\hline Total $(\mathbf{k W h})$ & $\mathbf{1 , 9 5}$ \\
\hline
\end{tabular}

Fonte: Autor.

Após a identificação do consumo por ciclo de produção, apresentados na Tabela 2, desenvolveram-se os cálculos para se chegar ao custo total de energia elétrica envolvido no processo, os quais são apresentados na Tabela 3. Considerando-se a tarifa de energia elétrica no valor de $\mathrm{R} \$ 0,49 / \mathrm{kWh}$, observase que o valor total de energia elétrica durante o processo é de $\mathrm{R} \$ 6,17$. 
Tabela 3 - Custos de energia elétrica envolvida no processo

\begin{tabular}{c|c|c|c}
\hline \multicolumn{2}{c|}{ Consumo total por ciclo (kWh): } & \multicolumn{2}{c}{ Custo total por ciclo (R\$): } \\
\hline Processo & Iluminação & Processo & Iluminação \\
\hline 10,64 & 1,95 & 5,22 & 0,96 \\
\hline \multicolumn{2}{r|}{ Total $(\mathrm{R} \$):$} & \multicolumn{2}{|c}{6,17} \\
\hline
\end{tabular}

Fonte: Autor.

O custo resultante mostrado na Tabela 3 é referente ao ciclo de produção. Este custo foi dividido pelo número de moldes que podem ser fixos no prato de cada braço da máquina de rotomoldagem, assim teremos o custo por produto. Para o presente estudo, o custo foi dividido por 8, o qual trata-se do número de moldes que os braços podem sustentar, resultando assim em um custo de $R \$$ 0,77 por peça.

Quanto ao consumo de GLP, seguiu-se a média histórica dos indicadores de consumo desta máquina, já que a mesma não possui nenhum sistema de medição. O consumo médio da mesma é de $0,3 \mathrm{~kg}$ de GLP para cada $1 \mathrm{~kg}$ de polietileno processado. O preço considerado foi de $\mathrm{R} \$ 3,13 / \mathrm{kg}$ de GLP. Desta forma, na Tabela 4 é apresentado o custo de GLP para a peça enfatizada neste estudo, o qual é de $\mathrm{R} \$ 6,10 / \mathrm{kg}$.

Tabela 4 - Consumo e custo de GLP

\begin{tabular}{r|c|c}
\hline Peso da peça $\mathbf{( k g )}$ & Gás consumido $\mathbf{( k g )}$ & $\mathbf{R} \mathbf{/ K g}$ \\
\hline 6,5 & 1,95 & 3,13 \\
\hline Total (R\$): & & $\mathbf{6 , 1 0}$ \\
\hline
\end{tabular}

Fonte: Autor.

Portanto, considerando-se os custos de energia elétrica para 8 moldes e os custos de consumo de GLP, tem-se o custo energético total para se produzir este produto de $R \$ 6,88$, salientando-se que são custos diretos dos consumidores de energia elétrica e GLP envolvidos no processo da máquina em estudo.

Durante um ano foram produzidas 192.000 peças, das quais 2.304 peças não puderam ser aproveitadas, pois não estavam em conformidade por algum motivo. Destas 2.304 peças, $67 \%$ apresentaram problemas relacionados com tempo de forno, isto é, 1.544 peças foram identificadas por falta de tempo, apresentando imperfeições, pois o polietileno não chegou a fundir totalmente. Também houve peças que apresentaram problemas de quebra durante a extração do molde, e outras identificadas durante o acabamento das mesmas, etapa onde também é realizada a inspeção de qualidade das peças produzidas. Estes últimos problemas estão relacionados com o excesso de tempo de forno. 
Com base nestes dados e informações de custos do processo, serão apresentados a seguir o consumo e o custo energético das peças que apresentaram problemas relacionados com o processo de forno. Para fins de cálculos e apresentação do custo e consumo energético, foi considerado o produto exemplificado no capítulo anterior.

Como já mencionado na metodologia deste trabalho, as peças não conformes, consideradas "peças mortas", devem ser trituradas, sendo posteriormente vendido a uma empresa recicladora. Para a etapa de trituração, é utilizado um moinho triturador, o qual possui um motor de $30 \mathrm{hp} \mathrm{e} \mathrm{capacidade}$ de trituração de $250 \mathrm{~kg} / \mathrm{h}$.

Considerando o índice de peças não conformes em relação a um período de um ano, e o produto em estudo, o desperdício chegaria a $10.036 \mathrm{~kg}$ de polietileno. Além disso, haveria consumo de energia elétrica para triturar este material. $\mathrm{O}$ consumo e custo para etapa de trituração das peças não conformes são apresentados na Tabela 5. De acordo com os valores apresentados, observase que o custo total de trituração é de $\mathrm{R} \$ 439,96$.

Tabela 5 - Consumo e custo para trituração

\begin{tabular}{r|c}
\hline \multicolumn{2}{c}{ Triturador } \\
\hline Potência $(\mathrm{kW})$ & 22,37 \\
\hline Tempo $(\mathrm{h})$ & 40,14 \\
\hline Total (KWh) & $\mathbf{8 9 7 , 8 8}$ \\
\hline
\end{tabular}

\begin{tabular}{r|c}
\hline \multicolumn{2}{c}{ Custo para trituração } \\
\hline Tarifa $(\mathrm{R} \$ / \mathrm{kWh})$ & 0,49 \\
\hline Consumo $(\mathrm{kWh})$ & 897,88 \\
\hline Total $(\mathbf{R} \$)$ & $\mathbf{4 3 9 , 9 6}$ \\
\hline
\end{tabular}

Fonte: Autor.

Diante disto, será apresentado na Tabela 6, o consumo e custo energético total que se teve para produzir as 1.544 peças que apresentaram problemas, levando em conta que para atender ao pedido houve a necessidade de se produzir novas peças.

Para se chegar ao custo total consumido, foi considerado a soma do custo do processo das peças não conformes (energia elétrica e GLP), o polietileno desperdiçado, o custo envolvido na trituração do polietileno desperdiçado, o custo do novo processo das peças a fim de atender ao pedido, e o polietileno para este novo processo. O polietileno triturado foi vendido para uma empresa recicladora, valor este sendo descontado do total dos custos. O custo total consumido foi de $\mathrm{R} \$ 135.048,88$. Foi considerado o valor de compra de $\mathrm{R} \$ 7,15$ / $\mathrm{kg}$ para polietileno extrudado, e o valor de venda de $\mathrm{R} \$ 3,00 / \mathrm{kg}$ para empresa recicladora.

O consumo energético total foi resultado da soma do custo do processo das peças não conformes (energia elétrica + GLP), consumo de energia para 
processo de trituração e consumo do novo processo, totalizando em 86.224,14 kWh.

Já na Tabela 7 apresenta-se o custo e o consumo da previsão para a produção do total de peças não conformes geradas durante o período de um ano de acordo com os dados mencionados anteriormente. Desta forma, a partir da Tabela 8, é possível apresentar uma comparação do custo consumido em relação ao programado. Após a análise das informações mostradas na Tabela 7 e Tabela 8, chega-se aos valores negativos apresentados, representando, assim, um prejuízo de $\mathrm{R} \$ 52.693,54$ o qual está relacionado ao consumo de 43.561,01 kWh.

Tabela 6 - Custo e consumo total

\begin{tabular}{r|c|c}
\hline & custo (R\$) & Consumo (kWh) \\
\hline Custo do processo das peças mortas (+) & $10.612,81$ & $42.663,13$ \\
\hline Polietileno desperdiçado (+) & $71.742,53$ & - \\
\hline Custo de energia elétrica para trituração (+) & 439,96 & 897,88 \\
\hline Custo do novo processo (+) & $10.612,81$ & $42.663,13$ \\
\hline Polietileno novo processado (+) & $71.742,53$ & - \\
\hline Polietileno triturado vendido (-) & $30.101,76$ & - \\
\hline Consumido: & $\mathbf{1 3 5 . 0 4 8 , 8 8}$ & $\mathbf{8 6 . 2 2 4 , 1 4}$ \\
\hline
\end{tabular}

Fonte: Autor.

Tabela 7 - Custo e consumo programado

\begin{tabular}{r|c|c}
\hline & Custo (R\$) & Consumo (kWh) \\
\hline Custo do processo (+) & $10.612,81$ & $42.663,13$ \\
\hline Polietileno processado (+) & $71.742,53$ & - \\
\hline Programado: & $\mathbf{8 2 . 3 5 5 , 3 4}$ & $\mathbf{4 2 . 6 6 3 , 1 3}$ \\
\hline
\end{tabular}

Fonte: Autor.

Tabela 8 - Custo e consumo programado $x$ consumido

\begin{tabular}{r|c|c|c|c|c}
\hline & PROGRAMADO & \multirow{4}{*}{$\mathrm{X}$} & CONSUMIDO & & Prejuízo \\
\cline { 1 - 1 } Custo (R\$) & $82.355,34$ & & & $-52.693,54$ \\
\cline { 1 - 2 } Consumo (kWh) & $42.663,13$ & & $86.224,14$ & & $-43.561,01$ \\
\hline
\end{tabular}

Fonte: Autor. 
Considerando o estudo desenvolvido, o qual se utilizou um produto específico e seu processo como exemplo, e as ações propostas neste trabalho, pode-se considerar os resultados não como prejuízo, e sim como economia para a empresa, pois, além da eficientização gerada através da otimização do consumo de energia elétrica e GLP, é possível citar os seguintes resultados positivos com a proposta deste trabalho:

- Garantia de produção de peças conformes de acordo com parâmetros definidos ou ajustados, evitando assim desperdícios de energias e de matéria-prima;

- Conscientização quanto ao consumo de combustível (GLP) e matériaprima derivados do petróleo, o qual é uma fonte de energia não renovável;

- O PCP passaria a ter liberdade e maior confiança para a programação e distribuição dos moldes nas máquinas de rotomoldagem através da classificação em famílias de acordo com parâmetros definidos;

- Pode-se citar também, que o custo de investimento será desprezível para implantação da proposta, sendo necessária apenas mudança no procedimento de trabalho dos setores envolvidos.

\section{CONCLUSÃO}

As indústrias vêm consumindo cada vez mais energia, tanto elétrica como térmica, a qual utiliza em muitos casos combustíveis oriundos de fontes energéticas não renováveis. Assim, torna-se necessário a realização de uma análise profissional de seus processos produtivos, a fim de propor ajustes e melhorias para alcançar a otimização do seu consumo.

Pensando nisto, se buscou através de uma investigação prática e com auxílio de referencial teórico, uma forma de apresentar propostas com o objetivo de melhorar a eficiência energética do processo produtivo de rotomoldagem, otimizando o consumo de energia elétrica e GLP, assim, mantendo e garantindo a qualidade dos produtos.

Através do acompanhamento do dia a dia do processo produtivo em estudo e do referencial teórico, puderam-se propor ações relacionadas à etapa de aquecimento, pois foi evidenciado que o processo estava resultando em peças não conformes com problemas de falta ou excesso de tempo de aquecimento dos moldes. A ação realizada teve o auxílio de um instrumento de medição, que por algum motivo não estava sendo bem aproveitado. Através deste foi possível definir e ajustar os parâmetros do processo, principalmente o parâmetro de tempo de forno, o qual foi identificado como sendo a principal causa dos problemas das peças não conformes. Durante o acompanhamento também foi evidenciado a má distribuição dos moldes nas máquinas de rotomoldagem, as quais passaram a ser programados com base na lista mestra dos moldes, trazendo mais liberdade e confiança para o PCP programar e produzir peças 
de boa qualidade. Outro ponto positivo do estudo é a conscientização quanto ao consumo dos energéticos por parte dos envolvidos no processo produtivo.

A partir da análise dos resultados referentes à peça estudada, observouse que do total de 192.000 peças produzidas no período de um ano, $1,2 \%$, ou seja, 2.304 peças não puderam ser aproveitadas, pois não estavam em conformidade. Observou-se também, que a principal causa de não conformidade está relacionada ao tempo de forno, ou seja, das 2.304 peças não conformes, $67 \%$, ou 1.544 peças, apresentaram problemas de imperfeições devido à falta de tempo no forno. Também houve peças que apresentaram problemas de quebra durante a extração do molde, e outras identificadas durante o acabamento das mesmas, etapa onde também é realizada a inspeção de qualidade das peças produzidas. Estes últimos problemas estão relacionados com o excesso de tempo de forno.

A partir dos problemas com o processo de forno descritos anteriormente, foi possível comparar os custos consumidos em relação aos programados. Considerando a soma do custo do processo das peças não conformes (energia elétrica e GLP), o polietileno desperdiçado, o custo envolvido na trituração do polietileno desperdiçado, o custo do novo processo das peças a fim de atender ao pedido, e o polietileno para este novo processo, chegou-se ao custo total consumido. Desta forma, observou-se um desperdício de 39\% nos custos de fabricação, ou seja, $\mathrm{R} \$ 52.693,54$ gastos devido aos problemas evidenciados no processo de forno.

Diante dos resultados apresentados é possível concluir que a eficientização de um processo produtivo não necessariamente precisa de altos investimentos. Muitas vezes o ajuste de alguns procedimentos internos pode trazer uma economia satisfatória, através da otimização do consumo de combustível, energia elétrica, e até mesmo de matéria-prima.

\section{REFERÊNCIAS}

BEALL, G. Rotational molding: design, materials, tooling and processing. Munich: Carl Hanser Verlag,1998.

CANEVAROLO JR, S. V. Ciência dos polímeros: um texto básico para tecnólogos e engenheiros. São Paulo, 2006.

COUTINHO, F. M. B.; MELLO, I. L; DE SANTA MARIA, L. C. Polietileno: principais tipos, propriedade e aplicações, 2003.

CRAWFORD, R.J.; KEARNS, M.P. Practical guide to rotational moulding. UK: Rapra Technology, 2003.

CRAWFORD, R. J.; THRONE, J. L. Rotational molding technology. Norwich, New York: Plastics Design Library, 2002. 
GODINHO, J. S. Property variations in polyethylene articles produced by a variety of moulding methods. Belfast: Queen's University of Belfast, 1997.

NUGENT, P. Rotational molding: a practical guide. USA: Paul Nugent, 2001.

ROTOLINE BRASIL. Disponível em: <http:/ / www.roline.com.br>. Acesso em: março de 2018.

\section{Apêndice A - Lista mestra de moldes}

\begin{tabular}{|c|c|c|c|c|c|c|c|c|c|c|c|c|c|c|}
\hline 节 & $\begin{array}{l}0 \\
.00 \\
0 \\
0 \\
0\end{array}$ & 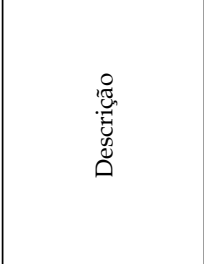 & 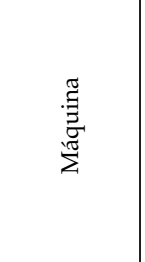 & 荦 & 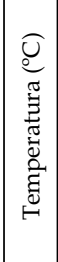 & 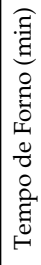 & 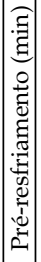 & 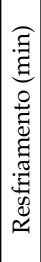 & 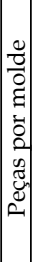 & 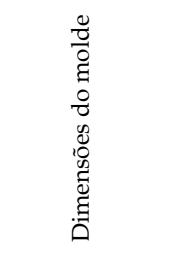 & 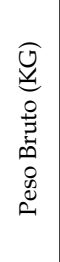 & 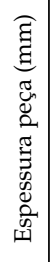 & نे & 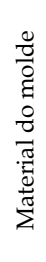 \\
\hline 10 & 10.4 .3 & FUNIL GRANDE & $\begin{array}{c}\text { ROTOLINE } \\
2.60\end{array}$ & $\mathrm{D}$ & 260 & 17 & 8 & 14 & 1 & $420 \times 300 \times 280$ & 3 & 5 & $\begin{array}{l}\text { VERMELHO } \\
\text { COD R-325 }\end{array}$ & $\mathrm{AL}$ \\
\hline 10 & 10.6 .3 & TUBO I & \begin{tabular}{|c|} 
ROTOLINE \\
2.60 \\
\end{tabular} & $\mathrm{D}$ & 260 & 17 & 8 & 14 & 1 & $380 \times 320 \times 280$ & 3 & 5 & $\begin{array}{l}\text { VERMELHO } \\
\text { COD R-325 }\end{array}$ & $\mathrm{AL}$ \\
\hline 10 & 10.18.3 & \begin{tabular}{|l|} 
TUBO \\
MULTIUSO \\
\end{tabular} & \begin{tabular}{|c|} 
ROTOLINE \\
2.60 \\
\end{tabular} & $\mathrm{D}$ & 260 & 17 & 8 & 14 & 1 & $700 \times 420 \times 350$ & 6,5 & 5 & $\begin{array}{l}\text { VERMELHO } \\
\text { COD R-325 }\end{array}$ & AL \\
\hline 18 & 18.16 .2 & TAMPA CAIXA & \begin{tabular}{|c|} 
ROTOLINE \\
2.60 \\
\end{tabular} & B & 260 & 16 & 7 & 14 & 1 & $550 \times 480 \times 300$ & 2,5 & 5 & $\begin{array}{c}\text { PRETA COD } \\
1700\end{array}$ & AL \\
\hline 18 & 18.17.2 & $\begin{array}{l}\text { CAIXA } \\
\text { TRASEIRA }\end{array}$ & \begin{tabular}{c|} 
ROTOLINE \\
2.60 \\
\end{tabular} & B & 260 & 16 & 7 & 14 & 1 & $600 \times 550 \times 170$ & 5,2 & 5 & $\begin{array}{c}\text { PRETA COD } \\
1700\end{array}$ & $\mathrm{AL}$ \\
\hline 18 & 18.19 .2 & \begin{tabular}{|l|} 
CAIXA \\
LATERAL \\
\end{tabular} & \begin{tabular}{|c|} 
ROTOLINE \\
2.60 \\
\end{tabular} & B & 260 & 16 & 7 & 14 & 1 & 590X550X155 & 4,7 & 5 & $\begin{array}{c}\text { PRETA COD } \\
1700 \\
\end{array}$ & $\mathrm{AL}$ \\
\hline 18 & 18.24 .2 & IENTAS & \begin{tabular}{|c|} 
ROTOLINE \\
2.60 \\
\end{tabular} & $\mathrm{D}$ & 260 & 17 & 8 & 14 & 1 & $940 \times 600 \times 220$ & 6,3 & 6 & $\begin{array}{c}\text { PRETA COD } \\
1700 \\
\end{array}$ & $\mathrm{AL}$ \\
\hline 18 & 18.25 .2 & \begin{tabular}{|l|} 
TAMPA \\
CAIXA DE \\
FERRAMENTAS \\
\end{tabular} & $\begin{array}{c}\text { ROTOLINE } \\
2.60\end{array}$ & $\mathrm{D}$ & 260 & 17 & 8 & 14 & 1 & $380 \times 350 \times 100$ & 1 & 6 & $\begin{array}{c}\text { PRETA COD } \\
1700\end{array}$ & $\mathrm{AL}$ \\
\hline 18 & 18.38.22 & REVESTIMENTO & \begin{tabular}{|c|} 
ROTOLINE \\
2.60 \\
\end{tabular} & A & 260 & 15 & 7 & 14 & 1 & $190 \times 190 \times 100$ & 0,4 & 4 & $\begin{array}{c}\text { CINZA CLARO } \\
\text { COD } 983 \\
\end{array}$ & $\mathrm{AL}$ \\
\hline 15 & 15.4.41 & \begin{tabular}{|l|} 
RESERVATORIO \\
1313 \\
\end{tabular} & \begin{tabular}{|c|} 
ROTOLINE \\
2.60 \\
\end{tabular} & A & 260 & 15 & $7 \mid$ & 14 & 1 & $480 \times 480 \times 300$ & 2,5 & 6 & $\begin{array}{c}\text { VERDE LIMÃO } \\
\text { COD } 803\end{array}$ & $\mathrm{AL}$ \\
\hline 15 & 15.5.42 & \begin{tabular}{|l|} 
TAMPA \\
RESERVATORIO \\
1313 \\
\end{tabular} & $\begin{array}{c}\text { ROTOLINE } \\
2.60\end{array}$ & A & 260 & 15 & 7 & 14 & 1 & $350 \times 300 \times 120$ & 0,7 & 5 & $\begin{array}{l}\text { VERDE MUSGO } \\
\text { COD } 805 \\
\end{array}$ & $\mathrm{AL}$ \\
\hline 15 & 15.15 .41 & $\begin{array}{l}\text { ESERVATORIO } \\
\mathrm{L}\end{array}$ & \begin{tabular}{|c|} 
ROTOLINE \\
2.60 \\
\end{tabular} & B & 260 & 16 & 7 & 14 & 1 & $560 \times 350 \times 275$ & 3,9 & 5 & $\begin{array}{c}\text { VERDE LIMÃO } \\
\text { COD } 803\end{array}$ & $\mathrm{AL}$ \\
\hline 15 & 15.16 .42 & \begin{tabular}{|l|} 
TAMPA \\
RESERVATORIO \\
$42 \mathrm{~L}$ \\
\end{tabular} & $\begin{array}{c}\text { ROTOLINE } \\
2.60\end{array}$ & A & 260 & 15 & 7 & 14 & 1 & $380 \times 260 \times 60$ & 0,4 & 3 & $\begin{array}{l}\text { VERDE MUSGO } \\
\text { COD } 805\end{array}$ & $\mathrm{AL}$ \\
\hline 15 & 15.27 .41 & $\begin{array}{l}\text { CAIXA DA } \\
\text { SEMENTE } 1515\end{array}$ & $\begin{array}{c}\text { ROTOLINE } \\
2.60\end{array}$ & B & 260 & 16 & 7 & 14 & 1 & $590 \times 450 \times 300$ & 5,0 & 5 & $\begin{array}{l}\text { VERDE LIMÃO } \\
\text { COD } 803\end{array}$ & $\mathrm{AL}$ \\
\hline 21 & 21.15 .2 & $\begin{array}{l}\text { PROTETOR } \\
\text { CARDAN } 270 \\
\end{array}$ & $\begin{array}{c}\text { ROTOLINE } \\
2.60 \\
\end{array}$ & C & 260 & 16 & 8 & 14 & 1 & Ø220X740 & 2,2 & 5,2 & $\begin{array}{c}\text { PRETA COD } \\
1700 \\
\end{array}$ & $\mathrm{AL}$ \\
\hline 21 & 21.16 .2 & $\begin{array}{l}\text { PROTETOR } \\
\text { CARDAN } 766 \\
\end{array}$ & \begin{tabular}{|c|} 
ROTOLINE \\
2.60 \\
\end{tabular} & C & 260 & 16 & 8 & 14 & 1 & Ø210X690 & 2,2 & 5,2 & $\begin{array}{c}\text { PRETA COD } \\
1700 \\
\end{array}$ & $\mathrm{AL}$ \\
\hline 21 & 21.19 .2 & \begin{tabular}{|l|} 
PROTEÇÃO \\
TÉRMICA \\
9575533 \\
\end{tabular} & $\begin{array}{c}\text { ROTOLINE } \\
2.60\end{array}$ & $\mathrm{D}$ & 260 & 17 & 8 & 14 & 2 & $560 \times 430 \times 225$ & 4,9 & 3 & $\begin{array}{l}\text { PRETA COD } \\
1700\end{array}$ & $\mathrm{AL}$ \\
\hline 21 & 21.23 .2 & \begin{tabular}{|l|} 
TAMPA DA \\
TOMADA 734 \\
\end{tabular} & \begin{tabular}{|c|} 
ROTOLINE \\
2.60 \\
\end{tabular} & B & 260 & 16 & 7 & 14 & 4 & $\varnothing 130 \times 150$ & 0,72 & 2,5 & $\begin{array}{c}\text { PRETA COD } \\
1700 \\
\end{array}$ & $\mathrm{AL}$ \\
\hline 21 & 21.24 .2 & SUPORTE 7340 & \begin{tabular}{|c|} 
ROTOLINE \\
2.60 \\
\end{tabular} & D & 260 & 17 & 8 & 14 & 4 & $150 \times 150 \times 60$ & 0,66 & 2,5 & $\begin{array}{c}\text { PRETA COD } \\
1700 \\
\end{array}$ & $\mathrm{AL}$ \\
\hline 21 & 21.25 .2 & TAMPA 762 & $\begin{array}{c}\text { ROTOLINE } \\
2.60 \\
\end{array}$ & D & 260 & 17 & 8 & 14 & 1 & $520 \times 240 \times 240$ & 2,6 & 4 & $\begin{array}{c}\text { PRETA COD } \\
1700 \\
\end{array}$ & $\mathrm{AL}$ \\
\hline
\end{tabular}




\begin{tabular}{|c|c|c|c|c|c|c|c|c|c|c|c|c|c|c|}
\hline 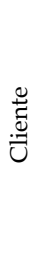 & $\begin{array}{l}80 \\
: 00 \\
0 \\
0 \\
0\end{array}$ & 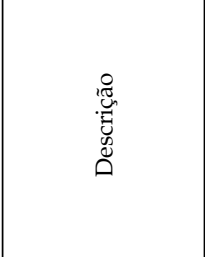 & 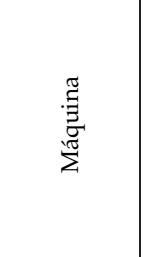 & 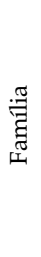 & 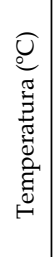 & 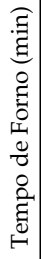 & 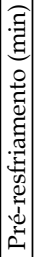 & 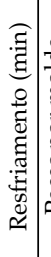 & 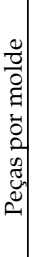 & 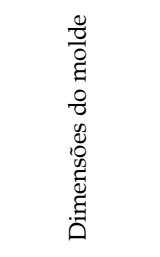 & 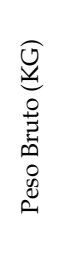 & 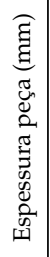 & نे & 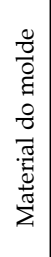 \\
\hline 12 & 12.22 .15 & \begin{tabular}{|l|} 
REFORÇO \\
INTERNO 704
\end{tabular} & $\begin{array}{c}\text { ROTOLINE } \\
2.60\end{array}$ & $\mathrm{C}$ & 260 & 16 & 8 & 14 & 1 & $330 \times 300 \times 140$ & 0,8 & 5 & $\begin{array}{c}\text { CINZA CHASSI } \\
\text { COD } 339\end{array}$ & $\mathrm{AL}$ \\
\hline 18 & 18.39 .22 & $\begin{array}{l}\text { REVESTIMENTO } \\
629\end{array}$ & \begin{tabular}{|l|} 
ROTOLINE \\
2.60
\end{tabular} & A & 260 & 15 & 7 & 14 & 1 & $670 \times 160 \times 130$ & 1,3 & 4 & $\begin{array}{c}\text { CINZA CLARO } \\
\text { COD } 983\end{array}$ & $\mathrm{AL}$ \\
\hline 18 & 18.40 .22 & CONSOLE 630 & \begin{tabular}{c|} 
ROTOLINE \\
2.60 \\
\end{tabular} & A & 260 & 15 & 7 & 14 & 1 & $600 \times 400 \times 400$ & 3,5 & 4 & $\begin{array}{c}\text { CINZA CLARO } \\
\text { COD } 983 \\
\end{array}$ & $\mathrm{AL}$ \\
\hline 12 & 12.23 .15 & \begin{tabular}{|l} 
PROTETOR \\
RADIADOR 704 \\
\end{tabular} & \begin{tabular}{|c|} 
ROTOLINE \\
2.60 \\
\end{tabular} & A & 260 & 15 & 7 & 14 & 1 & $600 \times 440 \times 400$ & 3,70 & 4 & $\begin{array}{c}\text { CINZA CHASSI } \\
\text { COD } 339 \\
\end{array}$ & AL \\
\hline 12 & 12.23 .2 & TAMPA 704 & \begin{tabular}{|l|} 
ROTOLINE \\
2.60 \\
\end{tabular} & $\mathrm{C}$ & 260 & 16 & 8 & 14 & 1 & $2900 \times 250 \times 90$ & 1,3 & 3 & $\begin{array}{c}\text { PRETA COD } \\
1700 \\
\end{array}$ & $\mathrm{AL}$ \\
\hline 19 & 19.5 .2 & $\begin{array}{l}\text { BICO CENTRAL } \\
511\end{array}$ & $\begin{array}{c}\text { ROTOLINE } \\
2.60 \\
\end{array}$ & B & 260 & 16 & 7 & 14 & 1 & $480 \times 420 \times 300$ & 5,44 & 6 & $\begin{array}{c}\text { PRETA COD } \\
1700 \\
\end{array}$ & $\mathrm{AL}$ \\
\hline 19 & 19.6 .2 & PORTA BICO 884 & \begin{tabular}{|c|} 
ROTOLINE \\
2.60 \\
\end{tabular} & B & 260 & 16 & 7 & 14 & 1 & $560 \times 300 \times 300$ & 3,8 & 5,2 & $\begin{array}{c}\text { PRETA COD } \\
1700 \\
\end{array}$ & $\mathrm{AL}$ \\
\hline 13 & 13.28.6 & \begin{tabular}{l|} 
REFORÇO \\
TANQUE 3100L
\end{tabular} & \begin{tabular}{|l|} 
ROTOLINE \\
2.60 \\
\end{tabular} & $\mathrm{C}$ & 260 & 16 & 8 & 14 & 1 & $500 \times 370 \times 250$ & 3,5 & 8 & $\begin{array}{l}\text { LARANJA } \\
\text { COD202 }\end{array}$ & $\mathrm{AL}$ \\
\hline 12 & 12.24 .15 & $\begin{array}{l}\text { REFORÇO } \\
\text { CAIXA 076 }\end{array}$ & $\begin{array}{c}\text { ROTOLINE } \\
2.60 \\
\end{array}$ & $\mathrm{C}$ & 260 & 16 & 8 & 14 & 1 & $280 \times 260 \times 130$ & 0,7 & 8 & $\begin{array}{c}\text { CINZA CHASSI } \\
\text { COD } 339\end{array}$ & $\mathrm{AL}$ \\
\hline 19 & 19.8.2 & $\begin{array}{l}\text { BICO LATERAL } \\
\text { DIR. } 008\end{array}$ & \begin{tabular}{|c|} 
ROTOLINE \\
2.60 \\
\end{tabular} & $\mathrm{D}$ & 260 & 17 & 8 & 14 & 1 & $600 \times 550 \times 260$ & 6,8 & 4 & $\begin{array}{c}\text { PRETA COD } \\
1700 \\
\end{array}$ & $\mathrm{AL}$ \\
\hline 19 & 19.9.2 & $\begin{array}{l}\text { BICO LATERAL } \\
\text { ESQ. } 009\end{array}$ & $\begin{array}{c}\text { ROTOLINE } \\
2.60 \\
\end{array}$ & $\mathrm{D}$ & 260 & 17 & 8 & 14 & 1 & $600 \times 550 \times 260$ & 6,8 & 4 & $\begin{array}{c}\text { PRETA COD } \\
1700 \\
\end{array}$ & $\mathrm{AL}$ \\
\hline
\end{tabular}

Fonte: Autor. 